\title{
Replication of the association between variants in WFS1 and risk of type 2 diabetes in European populations
}

\author{
P. W. Franks • O. Rolandsson • S. L. Debenham • \\ K. A. Fawcett $\cdot$ F. Payne $\cdot$ C. Dina $\cdot$ P. Froguel $\cdot$ \\ K. L. Mohlke • C. Willer • T. Olsson • N. J. Wareham • \\ G. Hallmans • I. Barroso • M. S. Sandhu
}

Published online: 15 January 2008

(C) Springer-Verlag 2007

Unfortunately there were some minor errors in this paper, as outlined below:

1. The reference to glucose levels in the legend of Table 2 and in the last paragraph of the Methods is redundant.

2. At the end of the Discussion the numbers of cases and controls are stated as 12,979 and 14,937 res-

The online version of the original article can be found at http://dx.doi. org/10.1007/s00125-007-0887-6.

P. W. Franks $(\bowtie) \cdot$ O. Rolandsson $\cdot$ T. Olsson $\cdot$ G. Hallmans

Department of Public Health and Clinical Medicine,

Umeå University Hospital,

Umeå, Sweden

e-mail: paul.franks@medicin.umu.se

URL: http://www.umu.se/phmed/medicin/paul.franks/

P. W. Franks · N. J. Wareham • M. S. Sandhu

MRC Epidemiology Unit, Institute of Metabolic Science,

Cambridge, UK

S. L. Debenham • M. S. Sandhu

Department of Public Health and Primary Care,

University of Cambridge,

Cambridge, UK pectively, whereas they should be 14,139 and 16,109 respectively, as correctly indicated elsewhere in the paper.

3. The overall $p$ value reported on the penultimate line of the Results is given as $p=5.4 \times 10^{-11}$, whereas it should read $4.9 \times 10^{-11}$, as correctly indicated elsewhere in the paper.

K. A. Fawcett $\cdot$ F. Payne $\cdot$ I. Barroso

Metabolic Disease Group, The Wellcome Trust Sanger Institute,

Hinxton, UK

C. Dina $\cdot$ P. Froguel

CNRS 8090-Institute of Biology, Pasteur Institute,

59019 Lille Cedex, France

K. L. Mohlke

Department of Genetics, School of Medicine,

University of North Carolina at Chapel Hill,

Chapel Hill, NC, USA

\section{Willer}

Department of Biostatistics and Center for Statistical Genetics,

University of Michigan,

Ann Arbor, MI 48109, USA 